\title{
Upstream Horizontal Mergers and Efficiency Gains
}

\author{
CHRYSOVALANTOU MiLLIOU \\ Apostolis PAVLOU
}

CESIFO WORKING PAPER NO. 2748

CATEGORY 11: INDUSTRIAL ORGANISATION

August 2009

\footnotetext{
An electronic version of the paper may be downloaded

- from the SSRN website: www.SSRN.com

- from the RePEc website: - from the CESifo website: 


\title{
Upstream Horizontal Mergers and Efficiency Gains
}

\begin{abstract}
We study upstream horizontal mergers and their potential efficiency gains. We show that an upstream horizontal merger can give rise to two efficiency-enhancing effects when firms trade through two-part tariffs. It increases R\&D investments and decreases wholesale prices when downstream competition is not too strong. Examining whether the merger's potential efficiency gains can overcome its anti-competitive effects in terms of welfare, we show that when firms merge usually both of the above mentioned efficiencies are realized and they are passed on to consumers. This holds to a lesser extend when firms trade through linear contracts.
\end{abstract}

JEL Code: L41, L42, L22.

Keywords: horizontal mergers, vertical relations, efficiency gains, two-part tariffs, merger policy.

\author{
Chrysovalantou Milliou \\ Department of International and European \\ Economic Studies \\ Athens University of Economics and \\ Business \\ Greece - Athens 10434 \\ cmilliou@aueb.gr
}

\author{
Apostolis Pavlou \\ Department of Economics \\ Athens University of Economics and \\ Business \\ Greece - Athens 10434 \\ pavlou@aueb.gr
}

July 2009

We would like to thank Stephane Caprice, George Deltas and Emmanuel Petrakis for their useful comments and suggestions. We would also like to thank seminar participants at the Toulouse School of Economics and at the CERGE-EI (Prague), as well as conference participants at the 7th International Industrial Organization Conference at Boston and at the 8th Conference on Research on Economic Theory and Econometrics at Tinos. Apostolis Pavlou wishes to thank his supervisor, Nikolaos Vettas, for his guidance. Financial support from the Basic Research Funding Program (BRFP) of the Athens University of Economics and Business is gratefully acknowledged. Full responsibility for all shortcomings is ours. 


\section{Introduction}

Horizontal mergers occur very often and in almost all markets. The antitrust authorities have traditionally been hostile towards them. Their hostility has been mainly based on the idea that a horizontal merger can increase monopoly power, thereby reducing competition and increasing prices. Horizontal mergers, however, may also alter firms' investment incentives and generate efficiency gains. The latter could play a crucial role in determining the effect of mergers on consumer and total welfare. Accordingly, the antitrust authorities should consider whether or not efficiency gains are likely to offset the mergers' anticompetitive effects. This is precisely the approach adopted in the most recent Merger Guidelines both in the U.S. and in EU. According to the former, the US Department of Justice "...will not challenge a merger if efficiencies are sufficient to reverse the merger's potential to harm consumers in the relevant market" (US Horizontal Merger Guidelines, 1997, section 4). Similarly, according to the new European Merger Guidelines, the Commission “... may decide that, as a consequence of the efficiencies the merger brings about, there are no grounds for declaring the merger incompatible with the common market." (EC Horizontal Merger Guidelines, 2004/03, art. 77).

Horizontal mergers in real world markets often take place among suppliers of intermediate products dealing with final product manufacturers or among wholesalers dealing respectively with retailers. ${ }^{1}$ In other words, horizontal mergers often occur between firms that operate in the upstream markets of vertically related industries. A special characteristic of horizontal mergers in vertically related industries is that they affect competition not only at the market level in which they take place but also at the other market level by altering, among other things, the terms of vertical trading.

In this paper, we study horizontal mergers in the upstream markets of vertically related industries when both the mergers and the upstream firms' R\&D investments are endogenous. We address a number of questions such as: Do upstream horizontal mergers lead to efficiency gains? Are they mainly motivated by increased market power or by cost-synergies? How do they influence the trading with the downstream firms? Can their potential cost-savings dominate their anti-competitive effects in terms of welfare? What is the role of the contract types used?

\footnotetext{
${ }^{1}$ See e.g., mergers among car equipment suppliers (Kolben-schmidt/Pierburg, Valeo/Engel), producers of chemical substances (BASF/Engelhard), and mobile phones manufacturers (Sony/Ericsson).
} 
We construct a model in which there are initially two upstream and two downstream firms. The upstream firms invest in cost-reducing $R \& D$ and the downstream firms produce differentiated goods. A four stage game is analyzed. In the first stage, the upstream firms decide whether or not they will merge. If they merge, they form an upstream monopolist. In the second stage, the R\&D investments are chosen by the upstream firm(s). In the following stage, if the merger has occurred then the newly formed upstream monopolist chooses the terms of the two-part tariff contracts that it offers to the two downstream firms. Otherwise, each of the two independent upstream firms chooses its terms of trade with its exclusive downstream customer. In the last stage, the downstream firms compete in quantities.

We demonstrate that an upstream horizontal merger can give rise to two distinct efficiencyenhancing effects. It increases the effective R\&D investments when products are not too close substitutes, and thus, downstream competition is not too strong. Moreover, it decreases the wholesale prices unless downstream competition is fierce and the R\&D technology is sufficiently efficient. The intuition for the merger's positive impact on $R \& D$ investments is that the output of a merged firm exceeds that of a separated firm because a merged firm sells its products to two instead of one downstream firms. Since the merged firm has larger output, it has stronger incentives to reduce its cost, and thus, to invest in R\&D. The decrease in the wholesale prices occurs for two reasons. The first reason is that the lower cost faced by the merged firm, due to its higher R\&D investments, allows it to charge lower wholesale prices. The second reason is that when an upstream firm increases the wholesale price it charges to one downstream firm, the rival downstream firm's output increases. Under two-part tariff contracts, the downstream production is subsidized; hence, the increase in the rival downstream firm's output constitutes a negative externality for the merged firm. Internalizing this negative externality, the merged firm decreases its wholesale prices.

We also demonstrate that upstream firms merge when products are not too close substitutes and the $R \& D$ technology is sufficiently efficient. Otherwise, they remain separated. Intuitively, when downstream competition is too fierce and $\mathrm{R} \& \mathrm{D}$ investments are too costly, the merger leads to both lower upstream cost-efficiency and lower wholesale prices. Thus, the upstream firms have a disincentive to merge. Instead, when downstream competition is rather weak, the merger leads to stronger upstream cost-efficiency; hence, the upstream firms have an incentive to merge. From this and our above mentioned findings regarding the merger's efficiencyenhancing effects, it follows that when firms merge, usually strong efficiency gains are realized. 
These efficiencies are passed on to the consumers since the lower wholesale prices translate into lower prices for the final products. As a result, when firms decide to merge, their merger usually increases both consumers and total welfare.

Extending our analysis to trading through wholesale price contracts, we find that the upstream firms always merge. There are two opposite efficiency effects in place then. The merger always increases the effective $\mathrm{R} \& \mathrm{D}$ investments but it also leads to higher wholesale prices when products are close substitutes. In the latter case, the merger is also welfare detrimental since it aggravates the severity of the double marginalization problem. In fact, an upstream horizontal merger is more likely to be welfare detrimental under wholesale price contracts than under two-part tariff contracts.

Our findings clearly indicate that an upstream horizontal merger's induced efficiency gains can overturn an otherwise anti-competitive merger into a pro-competitive one; hence, the antitrust authorities should seriously take into account efficiency gains in the assessment of upstream horizontal mergers. More specifically, in doing so, they should consider, among other things, the intensity of downstream competition and the contract type used.

There is an extensive literature on the efficiency gains of horizontal mergers in one-tier industries (see e.g., Farrell and Shapiro, 1990, Stenbacka, 1991, Motta and Vasconcelos, 2005, and Banal-Estañol et al., 2008). ${ }^{2}$ This literature has focused on the merger's impact on the market level in which it takes place and has not taken into account its potential impact on other market levels. This has started to change recently with a number of papers studying horizontal mergers in vertically related industries. Most of these papers have focused on the analysis of downstream horizontal mergers (see e.g., von Ungern-Sternberg, 1996, Dobson and Waterson, 1997, Inderst and Wey, 2003, Lommerud et al., 2005, Fauli-Oller and Bru, 2008, and Symeonidis, 2008). To the best of our knowledge the only papers on upstream horizontal mergers are those of Horn and Wolinsky (1988), Ziss (1995), O’Brien and Shaffer (2003), Inderst and Wey (2003), and Milliou and Petrakis (2007). ${ }^{3}$ With the exception of Inderst and Wey (2003) none of these papers have considered the potential efficiency gains of upstream horizontal mergers. Inderst and Wey (2003), in examining, among other things, how an upstream horizontal merger affects $R \& D$ investments, have considered a quite restrictive

\footnotetext{
${ }^{2}$ For a review of this literature see Roller et al. (2001).

${ }^{3}$ de Fontenay and Gans (2005) have also compared upstream monopoly with upstream competition but have focused on the incentives for vertical integration.
} 
environment in which there is no downstream competition and only one of the upstream firms can undertake a fixed $\mathrm{R} \& \mathrm{D}$ investment. We extend this literature by considering instead a market characterized by downstream competition, as well as by allowing for an endogenous level of $\mathrm{R} \& \mathrm{D}$ investments and for a number of different scenarios regarding the contractual arrangements used among the vertically related firms. Doing so, we contribute to the literature by providing an in depth analysis of the relationship between upstream horizontal mergers and efficiency gains.

The remainder of the paper is organized as follows. In Section 2, we present our model. In Section 3, we analyze the merger effects on R\&D investments and two-part tariff contracts. In Section 4, we explore firms' merger incentives. In Section 5, we extent our analysis to trading through wholesale price contracts. In Section 6, we perform a welfare analysis and draw some policy conclusions. In Section 7, we discuss a number of extensions of our model. We conclude in Section 8. All the proofs are relegated to the Appendix.

\section{The Model}

We consider a vertically related industry in which initially there are two upstream and two downstream firms denoted respectively by $U_{i}$ and $D_{i}$, with $i=1,2$. There is an exclusive relation between $U_{i}$ and $D_{i}{ }^{4}$ Each $D_{i}$ obtains an input from $U_{i}$, transforms it into a final product in a one-to-one relation and sells it to the final consumers facing the following (inverse) demand function:

$$
p_{i}=a-q_{i}-\gamma q_{j}, \quad i \neq j, \quad i, j=1,2, \quad 0 \leq \gamma<1,
$$

where $q_{i}$ and $p_{i}$ are respectively the quantity and the price of $D_{i}$ 's final product and $\gamma$ measures product substitutability. The higher is $\gamma$, the closer substitutes the products of $D_{i}$ and $D_{j}$ are.

The two upstream firms can merge or they can remain separated. If they remain separated, then each separate upstream firm $U_{i}$ faces a unit production cost given by $c-x_{i}$, where $x_{i}$ are

\footnotetext{
${ }^{4}$ This is a common assumption in the literature (see e.g., Horn and Wolinsky, 1988, Gal-Or, 1991, Lommerud et al., 2005, Milliou et al., 2007, and Milliou and Petrakis, 2007). Moreover, exclusive relations are common in many industries (e.g., car manufacturers often use exclusive car dealers, gasoline retailers are often bond to petroleum firms with exclusive contracts). An important source of exclusive relations is the existence of high switching costs. The latter can arise when the upstream firms produce inputs that are tailored for specific downstream firms.
} 
its cost-reducing R\&D investments and $c$, with $a>c>0$, is its initial unit production cost. In line with d'Aspremont and Jacquemin (1988) and many others, we assume that the R\&D investments are subject to diminishing returns, captured by the quadratic form of their cost, $m x_{i}^{2} / 2$, with $m>0$. Clearly, the higher is $m$ the lower is the efficiency of the R\&D technology.

If the two upstream firms merge, a monopolist, denoted by $U$, is formed in the upstream market. U's unit production cost is given by $c-x_{U}$, with $x_{U}$ denoting $U$ 's R\&D investments. U's R\&D investments decrease the production cost of the inputs that it sells to both downstream firms, i.e., its R\&D investments are not firm-specific. ${ }^{5}$ Similarly to the case of separate upstream firms, the cost of the R\&D investments of the upstream monopolist is $m x_{U}^{2} / 2$.

Each $D_{i}$ faces no other cost than the cost of obtaining the input from its upstream supplier. This cost includes a per-unit of input wholesale price, $w_{i}$, and a fixed fee, $f_{i}$, which constitutes a transfer from $D_{i}$ to its respective upstream supplier. Clearly, this means that trading between the upstream and downstream firms takes place through non-linear two-part tariff contracts.

Competitive interactions are modeled as a four-stage game with observable actions. In stage one, the upstream firms decide whether or not to merge horizontally. As mentioned above, when they merge they form an upstream monopolist. In stage two, the upstream firm(s) choose the level of their R\&D investments. In the following stage, stage three, the upstream firm(s) make take-it-or-leave-it offers to the downstream firms regarding their terms of trade. Finally, in stage four, the downstream firms compete in the final market in quantities. ${ }^{6}$

The above timing captures the idea that firms' merger decisions are strategic decisions with longer run characteristics than their decisions regarding $R \& D$ investments. This is a standard assumption in the literature (see e.g., Inderst and Wey, 2003, Fauli-Oller et al., 2007). The above timing also reflects our assumption that investments are noncontractible. In other words, we embody the standard incomplete contracts framework that corresponds to assuming that the specific contract terms are set after the investment stage. A standard justification for this assumption is the difficulty of contractually specifying all aspects of performance (see e.g., Grossman and Hart, 1986, Hart and Moore, 1988, and Segal, 1999).

\footnotetext{
${ }^{5}$ Alternatively, $U$ could undertake firm-specific R\&D investments, $x_{1}$ and $x_{2}$, such that its variable production cost is $\left(c-x_{1}\right) q_{1}+\left(c-x_{2}\right) q_{2}$. In our setting, $U$ earns higher profits when its $\mathrm{R} \& \mathrm{D}$ investments are not firm-specific than when they are firm-specific. Thus, $U$ prefers to undertake R\&D investments which are not firm-specific.

${ }^{6}$ Note that in our setting, as e.g., in Horn and Wolinsky (1988), Gal-Or (1991), McAfee and Schwartz (1995), and Milliou and Petrakis (2007), the contract terms are observed before downstream competition takes place. The case in which there is interim unobservability, i.e., a downstream firm does not observe its rival's contract terms in the last stage of the game, is discussed in Section 7.
} 
It is important to note that when the upstream firms merge then in the third stage of the game, the upstream monopolist makes its contract offers to the two downstream firms simultaneously and separately. This could simply be the case because the upstream monopolist has two representatives, each dealing with a different downstream firm. ${ }^{7}$ This means that the upstream monopolist can price discriminate among the downstream firms. ${ }^{8}$ As has been noted in the literature (see e.g., McAfee and Schwartz, 1995), multiple equilibria can arise in such settings due to the multiplicity of the beliefs that the downstream firms can form when they receive out-of-equilibrium offers. As in Horn and Wolinsky (1988), Cremer and Riordan (1987), O'Brien and Shaffer (1992), and Milliou and Petrakis (2007), we obtain a unique equilibrium by imposing pairwise proofness on the equilibrium contracts. That is, we require that a contract between $U$ and $D_{i}$ is immune to a bilateral deviation of $U$ with the rival downstream firm $D_{j}$, holding the contract with $D_{i}$ constant. $^{9}$

In order to guarantee that all the firms are active in the market in all the cases under consideration, we assume the following throughout the paper:

Assumption 1: $m>\frac{4\left(2-\gamma^{2}\right)\left(4-\gamma^{2}\right)^{2}}{\left(16-12 \gamma^{2}+\gamma^{4}\right)^{2}} \cdot{ }^{10}$

For notational reasons we use superscripts $S$ and $M$ to denote respectively the equilibrium values when the upstream firms have remained separated and when they have merged.

\section{Equilibrium R\&D Investments and Contract Terms}

In the last stage of the game, each $D_{i}$ chooses its output in order to maximize its gross profits:

$$
\max _{q_{i}} \Pi_{D_{i}}=\left(p_{i}-w_{i}\right) q_{i}=\left(a-q_{i}-\gamma q_{j}-w_{i}\right) q_{i}
$$

\footnotetext{
${ }^{7}$ This is a standard assumption in the literature on multilateral contracting (see e.g., Cremer and Riordan, 1987, Horn and Wolinsky, 1988, Hart and Tirole, 1990, O'Brein and Shaffer, 1992, McAfee and Schwartz, 1994 and 1995, and Rey and Vergé, 2004). For additional justifications of this assumption see McAfee and Schwartz (1995).

${ }^{8}$ In Section 7, we briefly discuss what could happen if price discrimination was not allowed.

${ }^{9}$ Hart and Tirole (1990), McAfee and Schwartz (1994, 1995), Rey and Vergé (2004), and de Fontenay and Gans $(2005,2006)$, among others use a similar assumption to that of pairwise proofness. They assume that downstream firms have passive beliefs, i.e., they require that when a downstream firm receives an out-ofequilibrium offer it continues to believe that its rival receives the equilibrium offer.

${ }^{10}$ Note that the right hand side of the inequality takes its highest value, 1.44 , when $\gamma=1$. The same condition is sufficient for the existence of a pure strategy equilibrium when there is an upstream monopolist which trades through two-part tariff contracts. For the potential non-existence of such equilibrium see e.g., McAfee and Schwartz (1994, 1995), Rey and Vergé (2004).
} 
The first order conditions give rise to the following reaction functions:

$$
R_{i}\left(q_{j}, w_{i}\right)=\frac{a-w_{i}-\gamma q_{j}}{2}
$$

As it can be seen, a decrease in the wholesale price charged to $D_{i}$ shifts its reaction function upwards and turns it into a more aggressive competitor in the final market. Solving the system of reaction functions (2), we obtain the Cournot equilibrium quantities expressed in terms of the wholesale prices:

$$
q_{i}\left(w_{i}, w_{j}\right)=\frac{(2-\gamma) a-2 w_{i}+\gamma w_{j}}{4-\gamma^{2}}
$$

In line with the above, we note that an increase in the wholesale price offered to $D_{i}$ decreases its output and at the same time increases the output of its rival, $D_{j}$.

\subsection{Separate Upstream Firms}

When the upstream firms remain separated, there are two competing vertical chains in the market. In stage three, each upstream firm $U_{i}$ chooses $w_{i}$ and $f_{i}$, taking as given $w_{j}$ and $f_{j}$, in order to maximize its net profits:

$$
\begin{aligned}
\max _{w_{i}, f_{i}} \Pi_{U_{i}} & =w_{i} q_{i}\left(w_{i}, w_{j}\right)+f_{i}-\left(c-x_{i}\right) q_{i}\left(w_{i}, w_{j}\right)-\frac{m x_{i}^{2}}{2} \\
\text { s.t. } \Pi_{D_{i}} & =\left[a-q_{i}\left(w_{i}, w_{j}\right)-\gamma q_{j}\left(w_{i}, w_{j}\right)-w_{i}\right] q_{i}\left(w_{i}, w_{j}\right) \geq f_{i}
\end{aligned}
$$

The participation constraint is binding; hence, $U_{i}$ 's maximization problem can be rewritten in the following way:

$$
\max _{w_{i}} \Pi_{U_{i}}=\left[a-q_{i}\left(w_{i}, w_{j}\right)-\gamma q_{j}\left(w_{i}, w_{j}\right)\right] q_{i}\left(w_{i}, w_{j}\right)-\left(c-x_{i}\right) q_{i}\left(w_{i}, w_{j}\right)-\frac{m x_{i}^{2}}{2} .
$$

One can easily see from (5) that $w_{i}$ is chosen in order to maximize the joint profits of $U_{i}$ and $D_{i}$. The first order conditions result in:

$$
w_{i}\left(x_{i}, x_{j}\right)=\frac{2 c\left[8-\gamma^{2}(4+\gamma)\right]-8 x_{i}\left(2-\gamma^{2}\right)+\gamma^{2}\left[a(\gamma(2+\gamma)-4)+2 \gamma x_{j}\right]}{16-12 \gamma^{2}+\gamma^{4}}
$$

Note that $\frac{\partial w_{i}}{\partial x_{i}}<0$. That is, the wholesale price that $U_{i}$ charges to $D_{i}$ decreases in its own cost-reducing $\mathrm{R} \& \mathrm{D}$ investments. At the same time though, its wholesale price increases in its 
rival's R\&D investments, $\frac{\partial w_{i}}{\partial x_{j}}>0$.

In the previous stage, stage two, each $U_{i}$ chooses its $\mathrm{R} \& \mathrm{D}$ investments in order to maximize its profits which can be found after substituting (6) into (5). The resulting equilibrium R\&D investments are:

$$
x_{i}^{S}=\frac{4(a-c)\left(8-6 \gamma^{2}+\gamma^{4}\right)}{m[4+(2-\gamma) \gamma]^{2}[4-\gamma(2+\gamma)]-4\left(8-6 \gamma^{2}+\gamma^{4}\right)}
$$

Interestingly, there is a U-shaped relationship between the intensity of downstream competition, measured by $\gamma$, and the upstream R\&D investments. More specifically, the upstream R\&D investments decrease in $\gamma$ if $\gamma<0.67$ and increase in $\gamma$ otherwise. Intuitively, recall that the constraint in (4) is binding, and thus, that the upstream firms extract all the downstream profits through the fixed fees. Given this, an increase in downstream competition has two countervailing effects on the upstream R\&D investments. First, more downstream competition means lower profit-margin for the upstream firms, and in turn, weaker upstream $R \& D$ investment incentives. Second, more downstream competition makes the advantage of increased efficiency more pronounced, and thus, increases the upstream R\&D investment incentives. When the products are close substitutes, the latter effect gets stronger and dominates the first effect. ${ }^{11}$

Substituting (7) into (6), we obtain the equilibrium wholesale prices:

$$
w_{i}^{S}=\frac{4 a\left(8-6 \gamma^{2}+\gamma^{4}\right)+m\left(16-12 \gamma^{2}+\gamma^{4}\right)\left[a \gamma^{2}-2 c(2+\gamma)\right]}{4\left(8-6 \gamma^{2}+\gamma^{4}\right)+m[4+(2-\gamma) \gamma]^{2}[\gamma(2+\gamma)-4]} .
$$

Note that $w_{i}^{S}<c-x_{i}^{S}$. In other words, the upstream firms subsidize their downstream customers since they set wholesale prices that are lower than their actual marginal cost. As mentioned above, an upstream firm, through a lower wholesale price transforms its downstream customer into a more aggressive competitor in the downstream market. This means that the reaction curve of its downstream firm shifts out. When firms compete in quantities their reaction curves are downward slopping and due to the shift the quantity of the rival downstream firm decreases while the quantity and gross profits of the own downstream firm increase. The upstream firm transfers, in turn, the higher downstream gross profits upstream via the fixed

\footnotetext{
${ }^{11}$ Sacco (2008) and Tishler and Milstein (2009) have also found a U-shaped relationship between product substitutability and cost-reducing R\&D investments. However, they have done so in an oligopolistic one-tier industry.
} 
fee.

Substituting (7) and (8) into (5), we obtain the equilibrium profits of a separate upstream firm:

$$
\Pi_{U_{i}}^{S}=\frac{2(a-c)^{2} m\left[m\left(16-12 \gamma^{2}+\gamma^{4}\right)^{2}\left(2-\gamma^{2}\right)-4\left(8-6 \gamma^{2}+\gamma^{4}\right)^{2}\right]}{\left[m(4+(2-\gamma) \gamma)^{2}(4-\gamma(2-\gamma))-4\left(8-6 \gamma^{2}+\gamma^{4}\right)\right]^{2}}
$$

\subsection{Upstream Merger}

In the event of merger, the newly formed upstream monopolist $U$ makes simultaneous and separate contract offers to the two downstream firms. In particular, in stage three, the upstream monopolist $U$ chooses both the wholesale price $w_{i}$ and the fixed fee $f_{i}$ that it offers to $D_{i}$, taking as given its equilibrium contract offer to $D_{j}$. Denoting the latter by $\left(w_{j}^{M}, f_{j}^{M}\right), w_{i}$ and $f_{i}$ are chosen to maximize $U$ 's net profits:

$$
\begin{aligned}
\max _{w_{i}, f_{i}} \Pi_{U}= & w_{i} q_{i}\left(w_{i}, w_{j}^{M}\right)+w_{j}^{M} q_{j}\left(w_{i}, w_{j}^{M}\right)-\left(c-x_{U}\right)\left[q_{i}\left(w_{i}, w_{j}^{M}\right)+q_{j}\left(w_{i}, w_{j}^{M}\right)\right] \\
& -\frac{m x_{u}^{2}}{2}+f_{i}+f_{j}^{M} \\
\text { s.t. } \Pi_{D_{i}}= & {\left[a-q_{i}\left(w_{i}, w_{j}^{M}\right)-\gamma q_{j}\left(w_{i}, w_{j}^{M}\right)-w_{i}\right] q_{i}\left(w_{i}, w_{j}^{M}\right) \geq f_{i} }
\end{aligned}
$$

The participation constraint (11) is binding. Therefore, (10) can be rewritten in the following way:

$$
\begin{aligned}
\max _{w_{i}} \Pi_{U}= & {\left[a-q_{i}\left(w_{i}, w_{j}^{M}\right)-\gamma q_{j}\left(w_{i}, w_{j}^{M}\right)\right] q_{i}\left(w_{i}, w_{j}^{M}\right)+w_{j}^{M} q_{j}\left(w_{i}, w_{j}^{M}\right) } \\
& -\left(c-x_{U}\right)\left[q_{i}\left(w_{i}, w_{j}^{M}\right)+q_{j}\left(w_{i}, w_{j}^{M}\right)\right]-\frac{m x_{u}^{2}}{2}+\Pi_{D_{j}}\left(w_{i}^{M}, w_{j}\right) .
\end{aligned}
$$

From the first order conditions of (12), we obtain the equilibrium wholesale prices expressed in terms of the R\&D investments:

$$
w_{i}\left(x_{U}\right)=\frac{4 c-\gamma^{2}(a+c)-x_{U}\left(4-\gamma^{2}\right)}{2\left(2-\gamma^{2}\right)}
$$

As expected, higher R\&D investments, and thus, lower upstream cost translate into lower wholesale prices, $\frac{\partial w_{i}}{\partial x_{U}}<0$.

We substitute (13) into (12) and we move to the previous stage, stage two, where $U$ chooses 
$x_{U}$ in order to maximize its profits. The resulting equilibrium $\mathrm{R} \& \mathrm{D}$ investments are:

$$
x_{U}^{M}=\frac{(a-c)\left(4-\gamma^{2}\right)(1-\gamma)}{m\left(2-\gamma^{2}\right)^{2}-4(1-\gamma)+\gamma^{2}-\gamma^{3}} .
$$

It can be easily confirmed that, in contrast to the separate upstream firms case, there is no longer a U-shaped relationship between downstream competition and upstream R\&D investments. Actually, in the merger case, as the goods become closer substitutes, and thus, the downstream competition becomes more intense, the investment incentives of the merged upstream firm always get weaker, $\frac{\partial x_{U}^{M}}{\partial \gamma}<0$. As mentioned before, one of the effects of an increase in downstream competition is that the advantage of having lower cost than your rival becomes more pronounced. We saw that this effect can cause the U-shaped relationship when the upstream firms remain separated. However, when the upstream firms merge, this effect is internalized by the merged firm because, in contrast to a separate one, it sells to both of the downstream firms.

Comparing the "effective" R\&D investments, that is, the cost-reduction that an upstream firm enjoys due to its R\&D investments, when the upstream firms merge and when they remain separated, we find the following.

Proposition 1 The equilibrium effective REDD investments are higher when the upstream firms merge than when they remain separated, $x_{U}^{M}>x_{i}^{S}$, if and only if $\gamma<\gamma_{x}=0.747$.

According to Proposition 1, an upstream horizontal merger can lead to higher R\&D investments. This occurs when the final products are not too close substitutes. Why is this so? There is a volume effect: A merged upstream firm, in contrast to a separate upstream firm, sells to two instead of one downstream firms, and thus, its output is larger. Since the merged firm produces more, its incentives to produce with a lower cost technology are stronger than those of a separate upstream firm. As a consequence, a merged firm has stronger incentives to invest in R\&D. Still, the volume effect is not the only effect in action. There is also the effect of an increase in downstream competition intensity captured by an increase in product substitutability. As we saw above, although the impact of an increase in product substitutability on $R \& D$ investments is always negative when firms merge, it is positive when firms remain separated and products are sufficiently close substitutes $(\gamma>0.67)$. Thus, when the products are sufficiently close substitutes, the effect of an increase in downstream competition could 
dominate the volume effect resulting into higher investments for the separated firm.

It should be noted that our above mentioned finding contrasts with that of Inderst and Wey (2003) according to which the incentives of an upstream firm to reduce its marginal cost always decrease with an upstream horizontal merger. This difference is mainly driven by the fact that in their setting, first, the level of $R \& D$ investments is exogenous, and second, the merger does not affect the supplied quantities since the demand of the downstream firms is independent.

Substituting (14) into (13) and then both of them into (12), we find the equilibrium wholesale prices and the upstream profits:

$$
\begin{aligned}
w_{i}^{M} & =\frac{2 a\left(4-\gamma^{2}\right)(-1+\gamma)-\left(2-\gamma^{2}\right) m\left[(a+c) \gamma^{2}-4 c\right]}{2\left[m\left(2-\gamma^{2}\right)^{2}-4+4 \gamma+\gamma^{2}-\gamma^{3}\right]} \\
\Pi_{U}^{M} & =\frac{(a-c)^{2} m\left(4-4 \gamma-\gamma^{2}+\gamma^{3}\right)}{2\left(4-4 \gamma-\gamma^{2}+\gamma^{3}-4 m+4 \gamma^{2} m-\gamma^{4} m\right)}
\end{aligned}
$$

Similarly to the case of separated upstream firms, the wholesale prices are lower than the upstream marginal cost, $w_{i}^{M}<c-x_{U}^{M}$. Why? The upstream monopolist suffers from a commitment problem. ${ }^{12}$ The source of this problem is its opportunistic behavior. More specifically, when $U$ makes its offer to $D_{i}$, it has an incentive to behave opportunistically. That is, it has an incentive to offer a lower wholesale price to $D_{j}$ in order to transform $D_{j}$ into an aggressive competitor in the final products market. The upstream monopolist has such an incentive because, via a higher fixed fee - upstream transfer, it will recoup its losses from selling the input below marginal cost to $D_{j}$ and it will also obtain higher net overall profits. This opportunistic behavior is anticipated by $D_{i}$. As a result, $D_{i}$ does not accept a wholesale price $w_{i} \geq c-x_{U}^{M}$.

The following Proposition informs us about the impact of an upstream horizontal merger on the equilibrium wholesale prices.

Proposition 2 The equilibrium wholesale prices are lower when the upstream firms merge than when they remain separated, $w_{i}^{M}<w_{i}^{S}$, if and only if $\gamma<\min \left\{1, \gamma_{w}(m)\right\}$, with $d \gamma_{w} / d m>0$, $\gamma_{w}(1.44)=0.844$ and $\gamma_{w}(2.4)=1$.

A merger leads to lower wholesale prices unless the products are sufficiently close substitutes ( $\gamma$ high) and the R\&D technology is sufficiently efficient ( $m$ low). In particular, this holds in

\footnotetext{
${ }^{12}$ For more details about the commitment problem see e.g., McAfee and Schwartz (1994), O'Brien and Shaffer (1992), and Rey and Vergé (2004).
} 
the area to the left of the $\gamma_{w}$ curve in Figure $1 .{ }^{13}$ Intuitively, there are two effects in action. First, there is an output effect that refers to the positive impact of an increase in the wholesale price $w_{i}$ charged to $D_{i}$ on the output of $D_{j}$. The increase in $D_{j}$ 's output constitutes a negative effect for the merged upstream firm since, as we saw above, $U$ subsidizes the downstream production and sells to both downstream firms. Internalizing the negative output effect, the merged upstream firm has weaker incentives to increase $w_{i}$ than a separate upstream firm. As demonstrated in Milliou and Petrakis (2007), in the absence of R\&D investments, the output effect alone would lead to the wholesale prices in the case of merger always being lower than the respective ones in the no-merger case. In our setting, however, there is an additional effect in action, a cost effect, due to the presence of $\mathrm{R} \& \mathrm{D}$ investments. The latter reduce the upstream cost, and thus, affect the wholesale prices that the upstream firms set. We saw in Proposition 1 that when products are sufficiently close substitutes, $R \& D$ investments are higher when the firms remain separated than when they merge. Clearly, this means that when products are sufficiently close substitutes, a separated firm faces a lower cost than a merged firm, and thus, it can charge a lower wholesale price. In other words, when products are close substitutes, the cost effect could dominate the output effect and lead to lower wholesale prices when firms remain separated. This occurs only when the $R \& D$ technology is sufficiently efficient because only then the cost effect is strong. When instead the R\&D investments are too costly, firms do not invest in $\mathrm{R} \& \mathrm{D}$ a lot and, in turn, the $\mathrm{R} \& \mathrm{D}$ investments do not influence the wholesale prices a lot.

\section{Merger Incentives}

We now turn to the examination of the upstream firms' incentives to merge. Our main conclusion is included in Proposition 3.

Proposition 3 The upstream firms merge, $\Pi_{U}^{M}>2 \Pi_{U_{i}}^{S}$, if and only if $\gamma<\min \left\{1, \gamma_{M}(m)\right\}$, with $d \gamma_{M} / d m<0$ and $\gamma_{M}(1.44)=0.961$.

Proposition 3 asserts that whether or not the upstream firms merge depends on the intensity of downstream competition and the efficiency of the R\&D technology. The upstream firms merge when products are not too close substitutes and the R\&D technology is sufficiently

\footnotetext{
${ }^{13}$ Note that in the horizontal axis $\gamma$ starts from 0.68 while in our model $\gamma \in[0,1)$.
} 
efficient. This occurs in the region to the left of the $\gamma_{M}$ curve in Figure 1. Intuitively, when downstream competition is not too fierce, the upstream R\&D investments are higher, and thus, the upstream cost-efficiency is stronger, when firms merge (Proposition 1). Clearly then, when downstream competition is not too fierce, the upstream firms have incentives to merge. When instead downstream competition is sufficiently fierce, the merger leads to both lower upstream cost-efficiency and stronger commitment problem, i.e., lower wholesale prices. The latter occurs only when the R\&D technology is sufficiently inefficient (Proposition 2). Since when both $\gamma$ and $m$ are high, the upstream firms enjoy higher cost-efficiency and suffer less from subsidization when they remain separated than when they merge, they have a disincentive to merge.

In a similar setting but without R\&D investments, Milliou and Petrakis (2007) have found that an upstream merger is never profitable independently of the degree of product substitutability. Therefore, the efficiency gains that can be realized when the merger takes place are pivotal for the profitability of a horizontal merger between upstream parties. In other words, it is the effect of the merger on the $R \& D$ investments that makes the merger profitable. This is a novel finding of our paper.

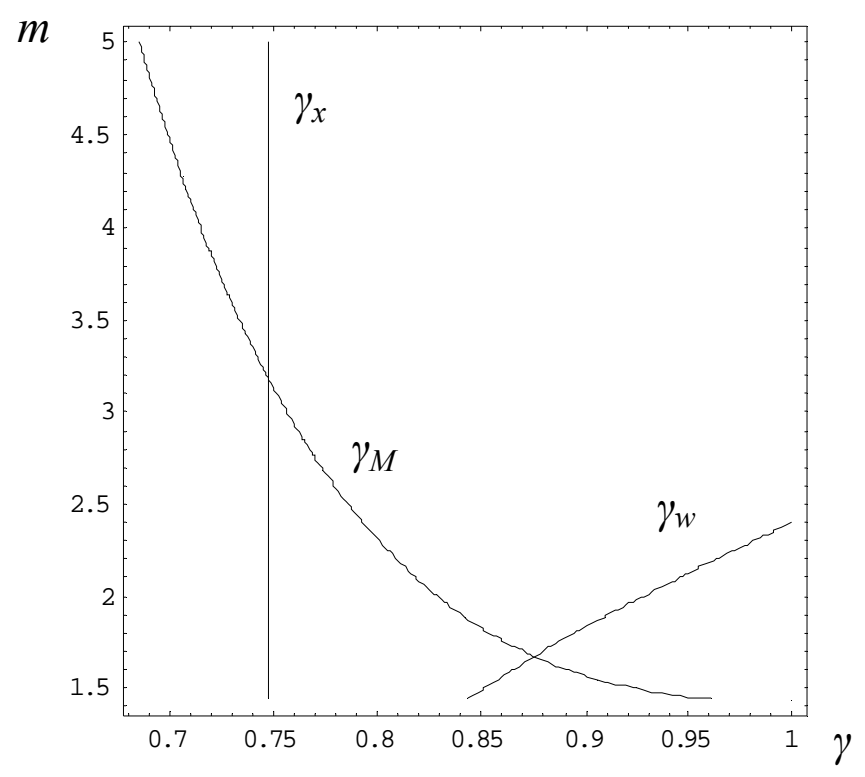

Figure 1: The critical values $\gamma_{x}, \gamma_{M}$, and $\gamma_{w}$ 


\section{$5 \quad$ Wholesale Price Contracts}

In this Section, we examine what happens when firms trade using linear contracts, i.e., contracts that consist of only a wholesale price $w_{i}$. The last stage of the game is identical to the respective one under two-part tariffs. Thus, the equilibrium quantities are given again by (3).

When the upstream firms remain separated, in stage three, each upstream firm $U_{i}$ faces the following maximization problem:

$$
\max _{w_{i}} \Pi_{U_{i}}=w_{i} q_{i}\left(w_{i}, w_{j}\right)-\left(c-x_{i}\right) q_{i}\left(w_{i}, w_{j}\right)-\frac{m x_{i}^{2}}{2} .
$$

From the system of first order conditions, we obtain the equilibrium wholesale prices in terms of the R\&D investments:

$$
w_{i}\left(x_{i}, x_{j}\right)=\frac{(4+\gamma)[2 c+a(2-\gamma)]-2 \gamma x_{j}-8 x_{i}}{16-\gamma^{2}}
$$

In stage two, each $U_{i}$ chooses the $\mathrm{R} \& \mathrm{D}$ investments that maximize its profits. We substitute (18) into (3) and then into (17) and we differentiate the latter in terms of $x_{i}$. Doing so we obtain the equilibrium R\&D investments:

$$
\widehat{x}_{i}^{S}=\frac{4(a-c)\left(8-\gamma^{2}\right)}{m(4+\gamma)(2+\gamma)\left(4-\gamma^{2}\right)-4\left(8-\gamma^{2}\right)}
$$

It is important to note that under wholesale price contracts, the $R \& D$ investments of a separate upstream firm always decrease with product substitutability, $\frac{\partial \widehat{x}_{i}^{S}}{\partial \gamma}<0$. In contrast thus to the two-part tariffs case, there is no U-shaped relationship between the intensity of downstream competition and the $R \& D$ investments of a separate upstream firm. This is mainly due to the fact that under wholesale price contracts, there are no fixed fees through which a separated upstream firm can transfer upstream all the profits of its downstream customer.

Substituting (19) into (18), we obtain the equilibrium wholesale prices:

$$
\widehat{w}_{i}^{S}=\frac{m(4-\gamma)(2+\gamma)(2(a+c)-a \gamma)-4 a\left(8-\gamma^{2}\right)}{m(4+\gamma)(2+\gamma)\left(4-\gamma^{2}\right)-4\left(8-\gamma^{2}\right)}
$$

Note that in contrast to the two-part tariffs case, under wholesale price contracts $\widehat{w}_{i}^{S}>c-\widehat{x}_{i}^{S}$.

Finally, substituting (19) and (20) into (1) and (17), we get the equilibrium profits of the 
separate upstream firms:

$$
\widehat{\Pi}_{U_{i}}^{S}=\frac{2 m(a-c)^{2}\left[m\left(4-\gamma^{2}\right)\left(16-\gamma^{2}\right)^{2}-4\left(8-\gamma^{2}\right)^{2}\right]}{\left[m(4+\gamma)(2+\gamma)\left(4-\gamma^{2}\right)-4\left(8-\gamma^{2}\right)\right]^{2}}
$$

When the upstream firms merge, the upstream monopolist $U$ faces the following maximization problem in stage three:

$$
\max _{w_{1}, w_{2}} \Pi_{U}=w_{1} q_{1}\left(w_{1}, w_{2}\right)+w_{2} q_{2}\left(w_{1}, w_{2}\right)-\left(c-x_{U}\right)\left(q_{1}\left(w_{1}, w_{2}\right)+q_{2}\left(w_{1}, w_{2}\right)\right)-\frac{m x_{U}^{2}}{2} .
$$

The resulting equilibrium wholesale prices expressed in terms of the $R \& D$ investments are:

$$
w_{i}\left(x_{U}\right)=\frac{a+c-x_{U}}{2}
$$

In stage two, $U$ chooses its $\mathrm{R} \& \mathrm{D}$ investments in order to maximize its profits that are obtained after substituting (23) into (22). The resulting equilibrium R\&D investments of the merged upstream firm are:

$$
\widehat{x}_{U}^{M}=\frac{a-c}{m(2+\gamma)-1} .
$$

Note that similarly to the no-merger case, the upstream R\&D investments decrease with the intensity of downstream competition, i.e., $\frac{\partial \widehat{x}_{U}^{M}}{\partial \gamma}<0$.

Substituting (24) into (23) and (22), we obtain the equilibrium wholesale prices, as well as the equilibrium profits of the merged upstream firm:

$$
\widehat{w}_{i}^{M}=\frac{m(a+c)(2+\gamma)-2 a}{2[m(2+\gamma)-1]} ; \quad \widehat{\Pi}_{U}^{M}=\frac{(a-c)^{2} m}{2[m(2+\gamma)-1]} .
$$

It should be noted that $\widehat{w}_{i}^{M}>c-\widehat{x}_{i}^{M}$. An upstream merged firm does not face a commitment problem under wholesale price contracts. The reason is that under wholesale price contracts it has one $\left(w_{i}\right)$ instead of two instruments $\left(w_{i}\right.$ and $\left.f_{i}\right)$ at hand. Thus, it does not have incentives to charge a lower wholesale price to a downstream firm in order to transform it into an aggressive competitor because it cannot transfer the downstream profits upstream through a fixed fee.

Proposition 4 Under wholesale price contracts,

(i) the equilibrium effective RED investments are always higher when the upstream firms merge than when they remain separated, $\widehat{x}_{u}^{M}>\widehat{x}_{i}^{S}$, 
(ii) the equilibrium wholesale prices are higher when the upstream firms merge than when they remain separated, $\widehat{w}_{i}^{M}>\widehat{w}_{i}^{S}$, if and only if $\gamma>\widehat{\gamma}_{w}(m)$, with $d \widehat{\gamma}_{w} / d m<0$ and $\widehat{\gamma}_{w}(1.44)=$ 0.554 ,

(iii) the upstream firms always merge.

Proposition 4(i) asserts that an upstream horizontal merger always reinforces firm's R\&D investment incentives. This result is driven by the volume effect that we mentioned in the intuition of Proposition 1. In contrast to the two-part tariffs case, the effect of an increase in downstream competition does not alter here the result. This is because under wholesale price contracts an increase in product substitutability always has a negative impact on $R \& D$ investments, independently of whether upstream firms have merged or not.

Horn and Wolinsky (1988) and Milliou and Petrakis (2007), under wholesale price contracts and in the absence of $R \& D$ investments, have found that the upstream merger always has a positive impact on wholesale prices. As they have explained this is due to the fact that an increase in the wholesale price charged to $D_{i}$ has a positive effect on the output of $D_{j}$. A merged upstream firm in contrast to a separate one, internalizes this positive output effect and sets higher wholesale prices. In contrast to them, we demonstrate in Proposition 4(ii) that an upstream merger does not always lead to higher wholesale prices. This occurs because the upstream R\&D investments are higher when the firms merge (Proposition 4(i)). As a consequence, a merged firm enjoys higher cost-efficiency which, in turn, allows it to charge lower wholesale prices than a separated firm. When the products are differentiated enough, the cost effect dominates the output effect and the wholesale prices turn out to be lower in the merger case.

According to Proposition 4(iii), an upstream horizontal merger always takes place under wholesale price contracts. Recall from above that such a merger has two distinct effects. First, it leads to higher upstream cost efficiency (Proposition 4(i)). Second, it leads to higher wholesale prices at least when the products are close substitutes (Proposition 4(ii)). In other words, a merger leads to higher upstream price-cost margin, and thus, to higher upstream profits which, in turn, result in the materialization of the merger. 


\section{Welfare Analysis and Policy Implications}

As we saw in the preceding Sections, a merger between the upstream firms alters the structure of the industry and affects firms' trading terms and R\&D investments. Clearly, these changes do not leave welfare unaffected. In this Section, we investigate the impact of a merger on consumers welfare (i.e., consumers surplus) and total welfare, as well as we discuss the policy implications of our findings.

Proposition 5 Under two-part tariff contracts,

(i) consumers surplus is higher when the upstream firms merge than when they remain separated, $C S^{M}>C S^{S}$, if and only if $\gamma<\min \left\{1, \gamma_{w}(m)\right\}$,

(ii) total welfare is higher when the upstream firms merge than when they remain separated, $T W^{M}>T W^{S}$, if and only if $\gamma<\min \left\{1, \gamma_{T W}(m)\right\}$, with $d \gamma_{T W} / d m>0, \gamma_{T W}(1.44)=0.868$ and $\gamma_{T W}(12)=1$.

From Proposition 5(i) and Proposition 2, it follows that, under two-part tariffs, a merger has a positive impact on consumers welfare only when it leads to lower wholesale price contracts. ${ }^{14}$ That is, when the products are not close substitutes, as well as when the products are close substitutes and the R\&D technology is sufficiently inefficient. Intuitively, when the products are not too close substitutes, the merger brings about two efficiency-enhancing effects. First, it increases the effective R\&D investments (Proposition 1), and second, it decreases the wholesale prices (Proposition 2). The wholesale prices lead to higher downstream output, and thus, to lower prices for the consumers. In contrast, when the products are too close substitutes and the $R \& D$ technology is sufficiently efficient, the merger harms the consumers since it increases the wholesale prices. According to Proposition 5(ii), an upstream horizontal merger leads to an increase in total welfare unless the products are too close substitutes and the R\&D technology is sufficiently efficient. This finding is a straightforward implication of the merger's impact on upstream profits (Proposition 3) and on consumers welfare (Proposition 5(i)).

\footnotetext{
${ }^{14}$ Note that the critical value $\gamma_{w}(m)$ in Proposition $5(\mathrm{i})$ and Proposition 2 is the same.
} 


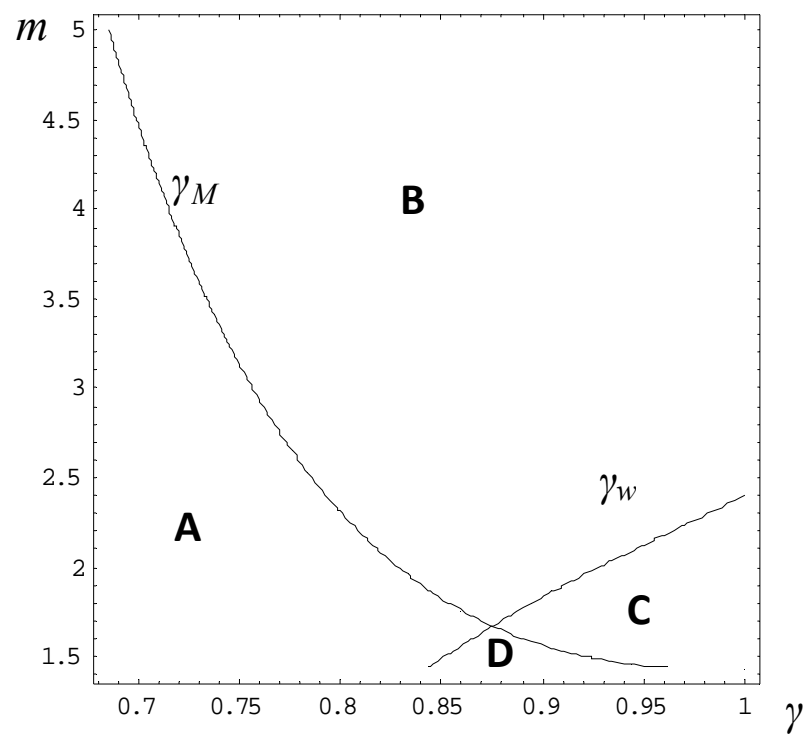

Figure 2: The critical values $\gamma_{M}$ and $\gamma_{w}$

We know from Proposition 3 that an upstream horizontal merger is materialized in the area to the left of the $\gamma_{M}$ curve in Figure 2, i.e., in areas A and D. We also know from Proposition 5(i) that an upstream horizontal merger is detrimental to consumers welfare in the area to the right of the $\gamma_{w}$ curve in Figure 2, i.e., in areas D and C. It follows from this, that only in area $\mathrm{D}$, where products are close substitutes and the $\mathrm{R} \& \mathrm{D}$ technology is quite efficient, a profitable merger reduces consumers welfare. In area A, and thus, in the majority of the cases, since $\gamma \epsilon[0,1)$, consumers welfare is enhanced when the merger takes place. It should be noted that qualitatively similar conclusions arise if we use as criterion total welfare instead of consumers welfare.

One might wonder how the merger would affect consumers welfare if firms traded through wholesale price contracts. We know from Proposition 4 that, under wholesale price contracts, a merger always increases the effective $\mathrm{R} \& \mathrm{D}$ investments but that it also leads to stronger double marginalization, at least when the products are close substitutes. Given this, we find that, under wholesale price contracts, the merger has a negative impact on consumers welfare in the area to the right of the $\gamma_{W}$ curve in Figure 3, i.e., when the products are close substitutes as well as when the products are not close substitutes and the R\&D technology is sufficiently inefficient. Comparing the case of two-part tariffs with the case of wholesale price contracts, we see that although upstream firms always merge under linear contracts, under two-part tariffs 
they merge usually only when strong efficiency gains are realized. Furthermore, while under wholesale price contracts a merger enhances consumers welfare in the area to the left of the $\gamma_{W}$ in Figure 3, under two-part tariff contracts it enhances consumers welfare in a much larger area, in the area to the left of the $\gamma_{w}$ curve.

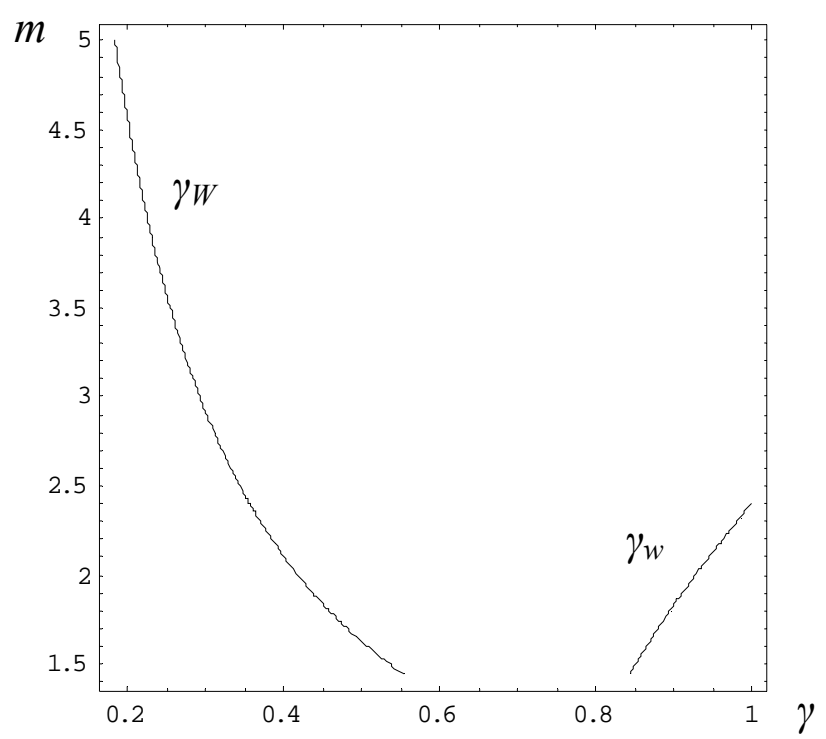

Figure 3: The critical values $\gamma_{w}$ and $\gamma_{W}$

One might also wonder whether the welfare implications of an upstream horizontal merger differ from those of a horizontal merger in an one-tier industry. In order to address this we consider the benchmark case in which there are two Cournot competitors in the market that produce differentiated goods and invest in cost-reducing R\&D. We find that their merger, which corresponds to the creation of a multi-product monopolist, always leads to both higher effective $\mathrm{R} \& \mathrm{D}$ investments and higher profits. Moreover, their merger reduces consumers surplus and total welfare in most of the cases and in a much larger area than an upstream horizontal merger does. ${ }^{15}$ This means, first, that the welfare implications of a horizontal merger in a one-tier industry differ from the respective ones of a horizontal merger in the upstream market of a two-tier industry, and second, that the efficiency gains of a horizontal merger in an one-tier industry usually do not pass on to consumers.

In terms of policy implications, the above findings suggest that in the assessment of upstream horizontal mergers, the antitrust authorities should indeed take into account the potential merger induced cost-synergies since the latter can overturn a merger's judgement. As

\footnotetext{
${ }^{15}$ The analysis is available from the authors upon request.
} 
it was mentioned in the Introduction, this is in line with the most recent Merger Guidelines in the U.S. that state that the US Department of Justice "...will not challenge a merger if efficiencies are sufficient to reverse the merger's potential to harm consumers in the relevant market" (US Horizontal Merger Guidelines, 1997, section 4). It is also in line with the new European Merger Guidelines according to which “... [The Commission] may decide that, as a consequence of the efficiencies the merger brings about, there are no grounds for declaring the merger incompatible with the common market." (EC Horizontal Merger Guidelines, 2004/03, art. 77). When, though, is it more likely that the merger's efficiency gains will turn an otherwise anti-competitive merger into a pro-competitive one? Our results indicate that the antitrust authorities should be much more cautious in the assessment of horizontal mergers in one-tier industries than in the assessment of upstream horizontal mergers since in the former case the efficiency gains pass on less to consumers. In addition, our results indicate that upstream horizontal mergers should raise more serious concerns for the antitrust authorities in industries in which downstream competition is quite intense, as well as in industries in which trading occurs through wholesale price contracts. Instead, the antitrust authorities should behave more leniently towards upstream horizontal mergers when downstream competition is weak, as well as when two-part tariff contracts are used.

\section{Discussion - Extensions}

In this Section, we discuss the robustness of our main results to a number of extensions and variations of our basic model.

- Uniform pricing: Throughout we have assumed that the upstream monopolist can price discriminate among the two downstream firms. One might wonder, however, what would happen if firms were operating in a regulated environment in which price discrimination was not allowed (see e.g., Caprice, 2006). The interesting case for consideration is under two-part tariff contracts. This is so because under wholesale price contracts the findings are exactly the same with and without price discrimination. Under two-part tariffs though the behavior of the upstream monopolist changes drastically when there is uniform pricing. More specifically, the upstream monopolist no longer suffers from the commitment problem. Thus, its contract offers are accepted if and only if the participation constraints of the downstream firms are satisfied. As a consequence, the upstream monopolist is able to commit to a higher wholesale price in 
comparison to the price discrimination case and to capture higher profits exploiting effectively its market power. Under this setting, the merger turns out to be always profitable and leads to higher effective R\&D investments. ${ }^{16}$ Whether the merger is desirable for the consumers and from a social viewpoint depends on the extent of the two opposite effects, the higher effective R\&D investments and the higher wholesale prices. We find that unless the products are sufficiently differentiated and the $R \& D$ investments are sufficiently efficient, the merger is welfare detrimental.

- Secret (interim unobservable) contracts: Our analysis has rested upon the assumption that contracts are interim observable, that is, they can be fully observed before downstream competition takes place in stage four. Here, we discuss briefly what happens if instead the terms of the two-part tariff contracts are unobservable by the downstream firms in the last stage of the game (see e.g., O’Brien and Shaffer, 1992, Rey and Vergé, 2004, and Rey and Tirole, 2006). In case of merger and interim unobservability, the upstream monopolist charges $w_{i}=c-x_{u}$. In contrast thus to the case with interim observability, the wholesale prices are not lower than the actual upstream marginal cost. This occurs because under interim unobservability the contract terms are not observed before the downstream competition stage, and thus, any possible strategic effect disappears. This also holds in the no-merger case with interim unobservability where each pair of vertical chain behaves as if it was vertically integrated and there is no distortion on the pricing by the upstream firms. Given this, a merger is always profitable and leads to higher effective R\&D and lower wholesale prices. With these two efficiency enhancing effects at play a merger is always pro-competitive.

- Downstream R\&D investments: We have assumed throughout that R\&D activities are undertaken by the upstream firm(s). Instead, one could investigate the situation where the downstream firms are the ones that invest in R\&D. When wholesale price contracts are used, then the downstream firms - by imposing their own mark-up - get positive profits. As a result, they have incentives to participate in $\mathrm{R} \& \mathrm{D}$ activities; however, an upstream horizontal merger, in the absence of upstream R\&D investments, makes the downstream firms worse-off. This is so because an upstream monopolist is in the position to charge higher wholesale prices than an independent upstream firm. Consequently, the profit squeeze, due to the merger, weakens the downstream firm's incentives to invest in R\&D. It follows that an upstream horizontal

\footnotetext{
${ }^{16}$ The equilibrium analysis is available from the authors upon request.
} 
merger in this case works to the detriment of consumers for two reasons. First, it increases the wholesale prices (double marginalization), and second, it reduces the effective $\mathrm{R} \& \mathrm{D}$ (decreases efficiency). ${ }^{17}$ When two-part tariff contracts are used, things become more complex since we should introduce some bargaining power to each party in order to be able to analyze the downstream firms' incentives to invest in $\mathrm{R} \& \mathrm{D}$. This is necessary because if the downstream parties obey to any take-it-or-leave-it offers by the upstream firms then they are left with no surplus (the upstream firms obtain all the downstream firms' profits through the fixed fees) and R\&D incentives disappear.

- Downstream price competition: In our basic model, downstream firms produce differentiated goods and compete in quantities. Here, we briefly discuss what would happen if downstream firms compete in prices. As demonstrated by Singh and Vives (1984), the demand function (1) faced by firm $i$ can be rewritten in the following way:

$$
q_{i}\left(p_{i}, p_{j}\right)=\frac{a(1-\gamma)}{1-\gamma^{2}}-\frac{1}{1-\gamma^{2}} p_{i}+\frac{\gamma}{1-\gamma^{2}} p_{j}
$$

Using the above demand function and assuming that in the last stage of the game downstream firms choose simultaneously and independently their prices, we are able to confirm the merger's efficiency-enhancing effects. In particular, we find that under two-part tariffs, similarly to the case with Cournot competition, the merger leads to an increase in the effective R\&D investments if and only if products are sufficiently differentiated. We also find that the merger leads to lower wholesale prices unless the products are sufficiently close substitutes. We should note though that now upstream firms do not subsidize the downstream production because since prices, in contrast to quantities, are strategic complements, an upstream firm does not wish its downstream customer to behave as an aggressive downstream competitor. As a consequence, an upstream merged firm faces a less severe commitment problem under Bertrand than under Cournot competition. It turns out that under Bertrand competition, independently of the intensity of downstream competition, the merger is desirable both from the upstream firms' viewpoint and the welfare viewpoint.

\footnotetext{
${ }^{17}$ The equilibrium analysis under wholesale price contracts is available from the authors upon request.
} 


\section{Concluding Remarks}

In this paper, we have examined whether or not horizontal mergers in upstream markets generate efficiency gains, as well as whether their potential efficiency gains can overcome their anti-competitive effects in terms of welfare. We have done so in a setting where both the upstream firms' merger decision and R\&D investments are endogenous.

We have shown that when firms trade through two-part tariff contracts, merger incentives are present when downstream competition is not too fierce and the R\&D investments are not too costly. This finding contrasts with the respective finding of Milliou and Petrakis (2007), according to which the upstream firms never merge under two-part tariff contracts. Our finding is driven by the presence of $R \& D$ investments and the positive impact of merger on them when products are not too close substitutes. In other words, when downstream competition is not too strong, the merger gives rise to efficiency gains. The higher R\&D investments translate into higher upstream cost-efficiency and lower wholesale prices and the latter lead, in turn, to lower prices for the consumers; hence, when products are not too close substitutes, the merger can be both profitable and pro-competitive.

We have also shown that under wholesale price contracts, even though the merger always leads to higher R\&D investments, it can also lead to higher wholesale prices when the products are close substitutes. The severity of the double marginalization problem increases then and the consumers end up paying higher prices. As a result, although the upstream firms always choose to merge, their merger reduces consumers welfare when downstream competition is strong.

Our findings clearly suggest that, in the treatment of upstream horizontal mergers, the antitrust authorities should take into account the mergers' impact on firm's investment incentives, i.e., their potential efficiency effects; however, their decision of whether or not they should allow horizontal mergers between upstream firms when there are potential efficiency gains should depend on a number of market characteristics, such as the form of vertical contract and the intensity of downstream competition.

Throughout the paper we have restricted our attention to situations where the upstream firms have all the bargaining power and the relations between the upstream and the downstream firms, in the absence of merger, are exclusive. It would be interesting to extend our analysis by examining what would happen when firms negotiate over their trading terms, as well as when 
the separated upstream firms have non-exclusive relations with the downstream firms.

\section{Appendix}

Proof of Proposition 1: We calculate the difference of the equilibrium R\&D investments in the case of an upstream merger (14) with the respective ones in the case of separate upstream firms (7): $M_{x}(\gamma, m) \equiv x_{U}^{M}-x_{i}^{S}$. Setting $M_{x}(\gamma, m)=0$ and solving for $\gamma$, we find $\gamma_{x}=0.747$. Moreover, we find that $\lim _{\gamma \rightarrow 0} M_{x}=\frac{m}{1-3 m+2 m^{2}}>0$ and $\lim _{\gamma \rightarrow 1} M_{x}=\frac{12}{12-25 m}<0$ for all $m$ that satisfy Assumption 1. It follows that $M_{x}(\gamma, m)>0$ if $\gamma<\gamma_{x}$ and $M_{x}(\gamma, m) \leq 0$ if $\gamma \geq \gamma_{x}$.

Proof of Proposition 2: We calculate the difference of the equilibrium wholesale prices in the case of an upstream merger (15) with the respective ones in the case of separate upstream firms (8): $M_{w}(\gamma, m) \equiv w_{i}^{M}-w_{i}^{S}$. Setting $M_{w}(\gamma, m)=0$ and solving for $\gamma$, we find $\gamma_{w}(m)=m_{w}^{-1}(\gamma)$, where $m_{w}(\gamma)=\frac{4\left(32-48 \gamma-24 \gamma^{2}+44 \gamma^{3}-8 \gamma^{5}+\gamma^{6}\right)}{\gamma^{3}\left(-32+40 \gamma^{2}-14 \gamma^{4}+\gamma^{6}\right)}$.

It can be checked that $\frac{d m_{w}}{d \gamma}>0$. Since $\frac{d m_{w}}{d \gamma}=1 /\left(\frac{d \gamma}{d m}\right)$, it follows that $\frac{d \gamma_{w}}{d m}>0$. We find that $m_{w}(\gamma)=1.44$ if and only if $\gamma=0.844$. Thus, $\gamma_{w}(1.44)=0.844$. Moreover, we find that $m_{w}(1)=2.4$. Clearly then, $\gamma_{w}(2.4)=1$.

Finally, we find $\lim _{\gamma \rightarrow 0} M_{w}=-\frac{m}{1-3 m+2 m^{2}}<0$ for all $m$ that satisfy Assumption 1 and $\lim _{\gamma \rightarrow 1} M_{w}=\frac{36-15 m}{-24+50 m}>0$ if and only if $m<2.4$. Thus, if $m>2.4$, then $M_{w}(\gamma, m)<0$ if $\gamma<\gamma_{w}(m)$ and $M_{w}(\gamma, m) \geq 0$ if $\gamma>\gamma_{w}(m)$. Otherwise, $M_{w}(\gamma, m)<0$ for all $\gamma$.

Proof of Proposition 3: We calculate the difference of the equilibrium profits of the merged upstream firm (15) with the sum of the equilibrium profits of the two separate upstream firms (8): $M_{M}(\gamma, m) \equiv \Pi_{U}^{M}-2 \Pi_{i}^{S}$. Setting $M_{M}(\gamma, m)=0$ and solving for $\gamma$, we find $\gamma_{M}(m)=$ $m_{M}^{-1}(\gamma)$

where $m_{M}(\gamma)=\frac{\begin{array}{c}4\left[1024(1-\gamma)-2048 \gamma^{2}+2304 \gamma^{3}+1600 \gamma^{4}-1920 \gamma^{5}-640 \gamma^{6}+720 \gamma^{7}+\right. \\ \left.158 \gamma^{8}-116 \gamma^{9}-24 \gamma^{10}+6 \gamma^{11}+2 \gamma^{12}+\sqrt{\left(8-6 \gamma^{2}+\gamma^{4}\right)^{2} R}\right]\end{array}}{\gamma^{4}\left(4+2 \gamma-\gamma^{2}\right)^{2}\left(4-2 \gamma-\gamma^{2}\right)^{2}\left(8+4 \gamma-3 \gamma^{2}-\gamma^{3}\right)}$,

with $R \equiv 16384+\gamma(-32768+\gamma(-24576+\gamma(90112+\gamma(-15360+\gamma(55296+\gamma(45568+\gamma(-46080$

$$
+\gamma(-9344+\gamma(18112+\gamma(192+\gamma(-3776+\gamma(192+\gamma(464+\gamma(464+\gamma(-36+\gamma(2+\gamma))))))))))))))))) \text {. }
$$


It can be checked that $\frac{d m_{M}}{d \gamma}<0$. Since $\frac{d m_{w}}{d \gamma}=1 /\left(\frac{d \gamma}{d m}\right)$, it follows that $\frac{d \gamma_{M}}{d m}<0$. Moreover, it can be checked that $m_{w}(\gamma)=1.44$ if and only if $\gamma=0.961$. Thus, $\gamma_{w}(1.44)=0.961$.

Finally, we find $\lim _{\gamma \rightarrow 0} M_{M}=\frac{m}{2-6 m+4 m^{2}}>0$ and $\lim _{\gamma \rightarrow 1} M_{w}=\frac{(288-200 m) m}{2(12-25 m)^{2}}<0$ for all $m$ that satisfy Assumption 1. Thus, $M_{M}(\gamma, m)>0$ if $\gamma<\gamma_{M}$ and $M_{M}(\gamma, m) \geq 0$ if $\gamma>\gamma_{M}$.

Proof of Proposition 4: (i) Using (24) and (19), we calculate:

$$
\widehat{x}_{U}^{M}-\widehat{x}_{i}^{S}=\frac{m(2+\gamma)\left(32-16 \gamma+\gamma^{3}\right)}{[-1+m(2+\gamma)] D_{1}(\gamma, m)}
$$

where $D_{1}(\gamma, m)=m(4+\gamma)(2+\gamma)(4-\gamma)^{2}-4\left(8-\gamma^{2}\right)$. The numerator of (26) is clearly positive. Regarding its denominator, we note that $[-1+m(2+\gamma)]>0$ while for $D_{1}(\gamma, m)$ we find that $\frac{\partial D_{1}}{\partial m}>0$. Thus, $D_{1}(\gamma, m)$ takes its smallest value when $m \rightarrow 1.44$. We find that $\lim _{m \rightarrow 1.44} D_{1}(\gamma, m)>0$. It follows from this that $D_{1}(\gamma, m)>0$. Since both the numerator and the denominator of (26) are positive, we have that $x_{U}^{M}-x_{i}^{S}>0$.

(ii) Using (25) and (20), we calculate:

$$
\widehat{w}_{i}^{M}-\widehat{w}_{i}^{S}=\frac{m(2+\gamma) N_{1}(\gamma, m)}{[-1+m(2+\gamma)] D_{1}(\gamma, m)}
$$

where $N_{1}(\gamma, m)=m \gamma(4-\gamma)(2+\gamma)(4+\gamma)-32$.

We know from the proof of part (i) that the denominator of (27) is positive. Regarding its numerator of (27), setting $N_{1}(\gamma, m)=0$ and solving for $m$, we find:

$$
\widehat{m}_{w}(\gamma)=\frac{32}{\gamma\left(32+16 \gamma-2 \gamma^{2}-\gamma^{3}\right)}
$$

Moreover, we find that $\lim _{\gamma \rightarrow 0} N_{1}(\gamma, m)=-32<0$ and $\lim _{\gamma \rightarrow 1} N_{1}(\gamma, m)=-32+45 m>0$. We find that $N_{1}(\gamma, 1.44)=0$ if and only if $\gamma=0.554$. Thus, $\widehat{w}_{i}^{M}-\widehat{w}_{i}^{S}>0$ if $\gamma>\widehat{\gamma}_{w}(m)$ and $\widehat{w}_{i}^{M}-\widehat{w}_{i}^{S} \leqslant 0$ if $\gamma<\widehat{\gamma}_{w}(m)$, with $\widehat{\gamma}_{w}(m)=\widehat{m}_{w}^{-1}(\gamma)$. Finally, it can be checked that $\frac{d \widehat{\gamma}_{w}}{d m}<0$.

(iii) Using (25) and (21), we calculate:

$$
\widehat{\Pi}_{U}^{M}-2 \widehat{\Pi}_{i}^{S}=\frac{m N_{2}(\gamma, m)}{2(2 m+\gamma m-1)\left[\gamma^{2}(4-24 m)+32 m \gamma-2 m \gamma^{3}+m \gamma^{4}-32(1-4 m)\right]^{2}}
$$

where $N_{2}(\gamma, m)=-28 m^{2} \gamma^{6}+4 m^{2} \gamma^{7}+m^{2} \gamma^{8}-1024(1-4 m)+m \gamma^{3}\left(16 \gamma^{2}-128\right)(1-8 m)$

$$
+256 \gamma^{2}\left(1-6 m+4 m^{2}\right)-16 \gamma^{4}\left(1-6 m-8 m^{2}\right) \text {. }
$$

The denominator of (28) is clearly positive since from Assumption 1 we have $m>1.44$. 
Regarding the numerator we find that $\frac{\partial N_{2}}{\partial m}>0$. Thus, the numerator takes its smallest value when $m \rightarrow 1.44$. We find that $\lim _{m \rightarrow 1.44} N_{2}>0$. Since both the numerator of $(28)$ are positive, it follows that $\widehat{\pi}_{U}^{M}-2 \widehat{\pi}_{i}^{S}>0$.

Proof of Proposition 5: (i) Consumers surplus is given by:

$$
C S^{k}=q_{i}\left(w_{i}^{k}, w_{i}^{k}\right)^{2}+\gamma q_{i}\left(w_{i}^{k}, w_{i}^{k}\right)^{2}
$$

with $k=M, S$ and $q_{i}\left(w_{i}^{k}, w_{i}^{k}\right)$ given by (3).

We calculate the difference $M_{C S}(\gamma, m) \equiv C S^{M}-C S^{S}$. Setting $M_{C S}(\gamma, m)=0$ and solving for $\gamma$, we find $\gamma_{C S}(m)=\gamma_{w}(m)$. See the properties of $\gamma_{w}(m)$ in the proof of Proposition 2 .

Finally, we find that $\lim _{\gamma \rightarrow 0} M_{C S}(\gamma, m)>0$ for all $m$ and $\lim _{\gamma \rightarrow 1} M_{C S}(\gamma, m)<0$ if and only if $m<2.4$. It follows that when $m<2.4$ then $C S^{M}-C S^{S}>0$ if and only if $\gamma<\gamma_{w}(m)$. When instead $m \geq 2.4$, then $C S^{M}-C S^{S}>0$ for all $\gamma$.

(ii) Total welfare in the case of upstream horizontal merger and in the case of separate upstream firms is given respectively by:

$$
T W^{M}=C S^{M}+\Pi_{U}^{M} \text { and } T W^{S}=C S^{S}+2 \Pi_{U_{i}}^{S} .
$$

We calculate the difference $M_{T W}(\gamma, m) \equiv T W^{M}-T W^{S}$. Setting $M_{T W}(\gamma, m)=0$ and solving for $\gamma$, we find $\gamma_{T W}(m)$. It can be checked that $d \gamma_{T W} / d m>0$. Setting $M_{T W}(\gamma, m)=$ 1.44 and solving for $\gamma$, we find $\gamma=0.868$. Thus, $\gamma_{T W}(1.44)=0.849$.

Finally, we find that $\lim _{\gamma \rightarrow 0} M_{T W}(\gamma, m)=\frac{m\left(2-9 m+8 m^{2}\right)}{4\left(1-3 m+2 m^{2}\right)^{2}}>0$ for all $m$ and $\lim _{\gamma \rightarrow 1} M_{T W}(\gamma, m)=$ $\frac{-12+m}{-24+50 m}<0$ if and only if $m<12$. It follows that when $m<12$ then $T W^{M}-T W^{S}>0$ if and only if $\gamma<\gamma_{T W}(m)$. When instead $m \geq 12$, then $T W^{M}-T W^{S}>0$ for all $\gamma$.

\section{References}

d'Aspremont, C. and A. Jacquemin (1988), "Cooperative and Non-cooperative R\&D in a Duopoly with Spillovers," American Economic Review, 78, 1133-1137.

Banal-Estañol, A., I., Macho-Stadler and J. Seldeslachts (2008), "Endogenous Mergers and Endogenous Efficiency Gains: The Efficiency Defence Revisited," International Journal of Industrial Organization, 26, 69-91. 
Caprice, S. (2006), "Multilateral Vertical Contracting with an Alternative Supply: The Welfare Effects of a Ban on Price Discrimination," Review of Industrial Organization, 28, 63-80.

Cremer, J. and M. H. Riordan (1987), "On Governing Multilateral Transactions with Bilateral Contracts," Rand Journal of Economics, 18, 436-451.

de Fontenay, C. C. and J. S. Gans (2005), "Vertical Integration in the Presence of Upstream Competition," Rand Journal of Economics, 36, 544-572.

de Fontenay, C. C. and J. S. Gans (2006), "Bilateral Bargaining with Externalities," unpublished manuscript, Melbourne Business School.

Dobson, P. and M. Waterson (1997), "Countervailing Power and Consumer Prices," Economic Journal, 107, 418-430.

Farrell, J. and C. Shapiro (1990), "Horizontal Mergers: An Equilibrium Analysis," American Economic Review, 80, 107-126.

Fauli-Oller, R. and L. Bru (2008), "Horizontal Mergers for Buyer Power," Economics Bulletin, 12, 1-7.

Fauli-Oller, R., J. Sandonis and J. Santamaria (2007), "Downstream Mergers and Upstream Investments," unpublished manuscript, University of Alicante.

Gal-Or, E. (1991), "Duopolistic Vertical Restraints," European Economic Review, 34, 1237 1253.

Grossman , S. J. and O. D. Hart (1986), "The Costs and Benefits of Ownership: A Theory of Vertical and Lateral Integration," Journal of Political Economy, 94, 691-719.

Hart, O. and J. Moore (1988), "Incomplete Contracts and Renegotiation," Econometrica, $56,755-785$.

Hart, O. and J. Tirole (1990), "Vertical Integration and Market Foreclosure," Brookings Papers on Economic Activity, Microeconomics, 205-276.

Horn, H. and A. Wolinsky (1988), "Bilateral Monopolies and Incentives for Mergers," Rand Journal of Economics, 19, 408-419.

Inderst, R. and C. Wey (2003), "Bargaining, Mergers, and Technology Choice in Bilaterally Oligopolistic Industries," Rand Journal of Economics, 34, 1-19.

Lommerud, K. E., O. R. Straume and L. Sorgard (2005), "Downstream Merger with Upstream Market Power," European Economic Review, 49, 717-743.

McAfee, P. and M. Schwartz (1994), "Opportunism in Multilateral Vertical Contracting: 
Nondiscrimination, Exclusivity, and Uniformity," American Economic Review, 84, 210-230.

McAfee, P. and M. Schwartz (1995), "The Non-Existence of Pairwise-Proof Equilibrium," Economics Letters, 49, 251-259.

Milliou, C. and E. Petrakis (2007), "Upstream Horizontal Mergers, Vertical Contracts, and Bargaining" International Journal of Industrial Organization, 25, 963-987.

Milliou, C., E. Petrakis and N. Vettas (2007), "(In)efficient Trading Forms in Competing Vertical Chains," unpublished manuscript, Athens University of Economics and Business.

Motta, M. and H. Vasconcelos (2005), "Efficiency Gains and Myopic Antitrust Authority in a Dynamic Merger Game," International Journal of Industrial Organization, 23, 777- 801.

O'Brien, D. and G. Shaffer (1992), "Vertical Control with Bilateral Contracts," Rand Journal of Economics, 23, 299-308.

O'Brien, D. and G. Shaffer (2003), "Bargaining, Bundling and Clout: The Portfolio Effects of Horizontal Mergers," Rand Journal of Economics, 36, 573-595.

Rey, P. and J. Tirole (2006), "A Primer on Foreclosure," in M. Armstrong and R. Porter (eds.), Handbook of Industrial Organization, Vol. 3, North-Holland, Amsterdam.

Rey, P. and T. Vergé (2004), "Bilateral Control with Vertical Contracts," Rand Journal of Economics, 35, 728-746.

Roller, L-H, J. Stennek and F. Verboven (2001), "Efficiency Gains from Mergers," European Economy, 5, 32-128.

Sacco, D. (2008), "Is There a U-shaped Relation between Competition and Innovation?," SOI Working Paper 0808, University of Zurich.

Salant, S. W., S. Switzer and R. J. Reynolds (1983), "Losses from Horizontal Merger: The Effect of an Exogenous Change in Industry Structure on Cournot-Nash Equilibrium," Quarterly Journal of Economics, 98, 185-199.

Segal, I. (1999), "Complexity and Renegotiation: A Foundation for Incomplete Contracts," Review of Economic Studies, 66, 57-82.

Stenbacka, L.R. (1991), "Mergers and Investments in Cost Reduction with Private Information," International Journal of Industrial Organization, 9, 397-405.

Symeonidis, G. (2008), "Downstream Competition, Bargaining and Welfare," Journal of Economics and Management Strategy, 17, 247-270.

Tishler, A. and I. Milstein (2009), "R\&D Wars and the Effects of Innovation on the Success and Survivability in Oligopolistic Markets," International Journal of Industrial Organization, 
$27,519-531$.

von Ungern-Sternberg, T. (1996), "Countervailing Power Revisited," International Journal of Industrial Organization, 14, 507-519.

Ziss, S. (1995), "Vertical Separation and Horizontal Mergers," Journal of Industrial Economics, 43, 63-75. 


\section{CESifo Working Paper Series}

for full list see www.cesifo-group.org/wp

(address: Poschingerstr. 5, 81679 Munich, Germany, office@cesifo.de)

2685 Peter Egger, Christian Keuschnigg and Hannes Winner, Incorporation and Taxation: Theory and Firm-level Evidence, June 2009

2686 Chrysovalantou Milliou and Emmanuel Petrakis, Timing of Technology Adoption and Product Market Competition, June 2009

2687 Hans Degryse, Frank de Jong and Jérémie Lefebvre, An Empirical Analysis of Legal Insider Trading in the Netherlands, June 2009

2688 Subhasish M. Chowdhury, Dan Kovenock and Roman M. Sheremeta, An Experimental Investigation of Colonel Blotto Games, June 2009

2689 Alexander Chudik, M. Hashem Pesaran and Elisa Tosetti, Weak and Strong Cross Section Dependence and Estimation of Large Panels, June 2009

2690 Mohamed El Hedi Arouri and Christophe Rault, On the Influence of Oil Prices on Stock Markets: Evidence from Panel Analysis in GCC Countries, June 2009

2691 Lars P. Feld and Christoph A. Schaltegger, Political Stability and Fiscal Policy - Time Series Evidence for the Swiss Federal Level since 1849, June 2009

2692 Michael Funke and Marc Gronwald, A Convex Hull Approach to Counterfactual Analysis of Trade Openness and Growth, June 2009

2693 Patricia Funk and Christina Gathmann, Does Direct Democracy Reduce the Size of Government? New Evidence from Historical Data, 1890-2000, June 2009

2694 Kirsten Wandschneider and Nikolaus Wolf, Shooting on a Moving Target: Explaining European Bank Rates during the Interwar Period, June 2009

2695 J. Atsu Amegashie, Third-Party Intervention in Conflicts and the Indirect Samaritan's Dilemma, June 2009

2696 Enrico Spolaore and Romain Wacziarg, War and Relatedness, June 2009

2697 Steven Brakman, Charles van Marrewijk and Arjen van Witteloostuijn, Market Liberalization in the European Natural Gas Market - the Importance of Capacity Constraints and Efficiency Differences, July 2009

2698 Huifang Tian, John Whalley and Yuezhou Cai, Trade Sanctions, Financial Transfers and BRIC's Participation in Global Climate Change Negotiations, July 2009

2699 Axel Dreher and Justina A. V. Fischer, Government Decentralization as a Disincentive for Transnational Terror? An Empirical Analysis, July 2009 
2700 Balázs Égert, Tomasz Koźluk and Douglas Sutherland, Infrastructure and Growth: Empirical Evidence, July 2009

2701 Felix Bierbrauer, Optimal Income Taxation and Public Goods Provision in a Large Economy with Aggregate Uncertainty, July 2009

2702 Marc Gronwald, Investigating the U.S. Oil-Macroeconomy Nexus using Rolling Impulse Responses, July 2009

2703 Ali Bayar and Bram Smeets, Government Deficits in the European Union: An Analysis of Entry and Exit Dynamics, July 2009

2704 Stergios Skaperdas, The Costs of Organized Violence: A Review of the Evidence, July 2009

2705 António Afonso and Christophe Rault, Spend-and-tax: A Panel Data Investigation for the EU, July 2009

2706 Bruno S. Frey, Punishment - and beyond, July 2009

2707 Michael Melvin and Mark P. Taylor, The Crisis in the Foreign Exchange Market, July 2009

2708 Firouz Gahvari, Friedman Rule in a Model with Endogenous Growth and Cash-inadvance Constraint, July 2009

2709 Jon H. Fiva and Gisle James Natvik, Do Re-election Probabilities Influence Public Investment?, July 2009

2710 Jarko Fidrmuc and Iikka Korhonen, The Impact of the Global Financial Crisis on Business Cycles in Asian Emerging Economies, July 2009

2711 J. Atsu Amegashie, Incomplete Property Rights and Overinvestment, July 2009

2712 Frank R. Lichtenberg, Response to Baker and Fugh-Berman's Critique of my Paper, "Why has Longevity Increased more in some States than in others?", July 2009

2713 Hans Jarle Kind, Tore Nilssen and Lars Sørgard, Business Models for Media Firms: Does Competition Matter for how they Raise Revenue?, July 2009

2714 Beatrix Brügger, Rafael Lalive and Josef Zweimüller, Does Culture Affect Unemployment? Evidence from the Röstigraben, July 2009

2715 Oliver Falck, Michael Fritsch and Stephan Heblich, Bohemians, Human Capital, and Regional Economic Growth, July 2009

2716 Wladimir Raymond, Pierre Mohnen, Franz Palm and Sybrand Schim van der Loeff, Innovative Sales, R\&D and Total Innovation Expenditures: Panel Evidence on their Dynamics, July 2009 
2717 Ben J. Heijdra and Jochen O. Mierau, Annuity Market Imperfection, Retirement and Economic Growth, July 2009

2718 Kai Carstensen, Oliver Hülsewig and Timo Wollmershäuser, Price Dispersion in the Euro Area: The Case of a Symmetric Oil Price Shock, July 2009

2719 Katri Kosonen and Gaëtan Nicodème, The Role of Fiscal Instruments in Environmental Policy, July 2009

2720 Guglielmo Maria Caporale, Luca Onorante and Paolo Paesani, Inflation and Inflation Uncertainty in the Euro Area, July 2009

2721 Thushyanthan Baskaran and Lars P. Feld, Fiscal Decentralization and Economic Growth in OECD Countries: Is there a Relationship?, July 2009

2722 Nadia Fiorino and Roberto Ricciuti, Interest Groups and Government Spending in Italy, 1876-1913, July 2009

2723 Andreas Wagener, Tax Competition, Relative Performance and Policy Imitation, July 2009

2724 Hans Fehr and Fabian Kindermann, Pension Funding and Individual Accounts in Economies with Life-cyclers and Myopes, July 2009

2725 Ernesto Reuben and Arno Riedl, Enforcement of Contribution Norms in Public Good Games with Heterogeneous Populations, July 2009

2726 Kurt Schmidheiny and Marius Brülhart, On the Equivalence of Location Choice Models: Conditional Logit, Nested Logit and Poisson, July 2009

2727 Bruno S. Frey, A Multiplicity of Approaches to Institutional Analysis. Applications to the Government and the Arts, July 2009

2728 Giovanni Villani, A Strategic R\&D Investment with Flexible Development Time in Real Option Game Analysis, July 2009

2729 Luca Di Corato and Michele Moretto, Investing in Biogas: Timing, Technological Choice and the Value of Flexibility from Inputs Mix, July 2009

2730 Gilad D. Aharonovitz, Nathan Skuza and Faysal Fahs, Can Integrity Replace Institutions? Theory and Evidence, July 2009

2731 Michele Moretto and Sergio Vergalli, Managing Migration through Conflicting Policies: an Option-theory Perspective, July 2009

2732 Volker Nitsch, Fly or Cry: Is Airport Noise Costly?, July 2009

2733 Francesco Cinnirella and Joachim Winter, Size Matters! Body Height and Labor Market Discrimination: A Cross-European Analysis, July 2009 
2734 Samuel Bowles and Sandra Polanía Reyes, Economic Incentives and Social Preferences: A Preference-based Lucas Critique of Public Policy, July 2009

2735 Gary Burtless, Lessons of the Financial Crisis for the Design of National Pension Systems, July 2009

2736 Helmuth Cremer, Firouz Gahvari and Pierre Pestieau, Fertility, Human Capital Accumulation, and the Pension System, July 2009

2737 Hans Jarle Kind and Frank Stähler, Market Shares in Two-Sided Media Industries, July 2009

2738 Pamela Campa, Alessandra Casarico and Paola Profeta, Gender Culture and Gender Gap in Employment, August 2009

2739 Sebastian Gechert, Supplementary Private Health Insurance in Selected Countries: Lessons for EU Governments?, August 2009

2740 Leif Danziger, Endogenous Monopsony and the Perverse Effect of the Minimum Wage in Small Firms, August 2009

2741 Yan Dong and John Whalley, A Third Benefit of Joint Non-OPEC Carbon Taxes: Transferring OPEC Monopoly Rent, August 2009

2742 Valentina Bosetti, Carlo Carraro and Massimo Tavoni, Climate Change Mitigation Strategies in Fast-Growing Countries: The Benefits of Early Action, August 2009

2743 Christina Felfe, The Willingness to Pay for Job Amenities: Evidence from Mothers' Return to Work, August 2009

2744 Jörg Franke, Christian Kanzow, Wolfgang Leininger and Alexandra Väth, Effort Maximization in Asymmetric N-Person Contest Games, August 2009

2745 Bruno S. Frey and Paolo Pamini, Making World Heritage Truly Global: The Culture Certificate Scheme, August 2009

2746 Frank N. Caliendo, Is Social Security behind the Collapse of Personal Saving?, August 2009

2747 Caterina Liesegang and Marco Runkel, Corporate Income Taxation of Multinationals and Fiscal Equalization, August 2009

2748 Chrysovalantou Milliou and Apostolis Pavlou, Upstream Horizontal Mergers and Efficiency Gains, August 2009 